\title{
From Passive White Cube Viewer to Active Black Cube User: Tracking Changes in Museum Environments via "Interactive" Installation Art (Analogue to Digital 1968-2008)
}

\author{
Cyrus Manasseh, University of Western Australia, Western Australia, \\ Australia
}

\begin{abstract}
In many countries of the world, the art gallery used to be mainly a site for contemplation. Now today, many contemporary gallery spaces globally, are sites for 'entertainment' or 'play', in which audiences are immersed in cinematic programmes, or are forced to interact more directly with the works. From the late 1960 s many artists' works worldwide had posed challenges to the institutional framework of the Modernist art museum which had been initiated in New York by the Museum of Modern Art (MoMA) in 1929. Much of this was commandeered by artists who would employ the latest form of art and technology such as video art to critique institutional structures. While the accessibility of video technology to artists by the mid-1970s was less than a decade old the process of commodifying the form of video art had progressed in earnest by the major institutional galleries largely from the late 1960s. Yet the ability of mainstream/large scale galleries such as MoMA or those that would follow MoMA to reconfigure their spatial flexibility would take some time. Central to the urgency of meeting their commitments to commodify the form (as a legitimate form of contemporary art) would be the critique of gallery structures by the artists themselves. The galleries wanting to incorporate this work lacked the ability (largely) to accomplish this. The paper tracks the development of the contemporary art museum/gallery framework (from 'White Cube' to 'Black Cube' paradigm) from a period of high-tolate modernism until the present day (i.e. 1968-2008).
\end{abstract}

Keywords: Active, Analogue, Audience, Change, Computer, Context, Digital, Frameworks, Gallery, Interactive, Multi-Media, Participation, Passive, Space, Video

\section{Introduction}

$\mathrm{T}$

HIS PAPER LOOKS at how attempts to create the 'total work' of art via technology ('Time Art') would help inspire the development of a new kind of museum type that now limits the predominance of the 'White Cube's' role and popularity for contemporary art propagation/exhibition as established by New York's MoMA in 1929. It discusses how and why, within a period of High Modernism 1968-1990 app., the artists' attempts to create the 'total work/total experience of art' particularly via the 'time-based' medium of analogue video art/video installation would help to alter the shape of the art museum for the twenty-first century.

Nowadays, contemporary art museums have increasingly become interactive spaces often offering viewers environments which differ considerably to those of the traditional art mu-

The International Journal of the Arts in Society

Volume 4, 2009, http://www.arts-journal.com, ISSN 1833-1866 
seums of the past. In the past, from the Louvre Museum to MoMA, the 'hierarchical'1 art museum would be a temple separating high art from the world outside as a way to provide a sacred place/ space for quiet contemplation. Yet in these hierarchical contexts for display, art was not meant to be touched by the visitor. In contrast, today's contemporary art museums are increasingly designed to provoke live audience interaction or interactivity with the exhibits and now furnish significant exhibition space for moving image exhibition/installation in often darkened or 'Black Cube' anti-hierarchical display environments where art is often meant to be touched. Significantly it would be the merging of time-based art with the idea of the 'total work' by artists that would be central to the development of the contemporary art museum/gallery framework (from 'White Cube' to 'Black Cube' paradigm) from a period of high-to-late Modernism until the present day (i.e. 1968-2008). As a result of the 'time factor' within temporalized forms of installation art such as analogue video art and video installation being introduced into traditional and Modernist 'White Cube' museum structures as total (electronic) works from the 1960s, these museums would need to alter or modify their viewing environments within a period of high -to-late Modernism. Thus shaped by 'Time Art' ${ }^{2}$ these new environments, in a sense, would need to epitomize a 'carnival aspect' within anti-hierarchical display environments to provide an increasingly popular alternative to the ideological function of the traditional and Modernist gallery paradigms that had been designed to separate art out from the everyday world. Through this, many contemporary art museums today would often encourage their interior spaces to epitomize the world outside through the way many of their objects are exhibited and communicated.

Prior to this, as early as the early twentieth century, the initial breaking down of art institutional structures and the confines of traditional painting and sculpture by the art being produced had actually, in a sense, already begun by artists who had exploded out from being confined by traditional painting and sculpture in enormously varied ways. These artists would incorporate new materials into their art bound by a common purpose: to epitomize or be at one with everyday life. Braque and Picasso's ideas in the early twentieth century to incorporate everyday materials into their works would reflect attempts to break beyond the confines of the traditional canvas indicating a move forwards for numerous twentieth century artists, from the Russians Malevich and Tatlin, to Pollock circa mid 1950s. ${ }^{3}$

More recently, mirroring the speed and extent to which the planet has become networked electronically the huge expansion of art practices, which would exist far beyond traditional painting and sculpture now almost frenetically employ all manner/forms of everyday items. In today's art, all things that can be analyzed, broken down and dissected as a subject have almost certainly been included in an artwork someplace by someone which would be indicative of a general shift away from objectivity to subjectivity and personal expression. Among this would be art that would be produced out of the technological revolution. Technologybased art, or 'Time Art' would encompass a range of practices from photography to film to

\footnotetext{
${ }^{1}$ In regard to my use of the term 'hierarchical' both the paradigms/ contexts of the Louvre and MoMA would present their art in a hierarchical way. That is, they would usually present artworks in a prescribed sequenced which would depend upon a doctrinaire system of classification. See Duncan and Wallach. 'The Universal Survey Museum' 448-69. See also Duncan and Wallach 'MOMA: Ordeal and Triumph on 53 ${ }^{\text {rd }}$ Street', 48-57.

2 Initially, 'time based art' had begun in 1883 with photography and had been followed by early experiments in film from the late nineteenth century and from 1963 by analogue video art and then digital art which became increasing popular from the early 1990s.

${ }^{3}$ Rush, New Media in Late $20^{\text {th }}$ Century Art, 7.
} 
video to virtual reality - (with the last two in particular often aspiring to be total artworks within the museum/gallery). Significantly in particular, it would be the incorporation of video art often integrally linked with Performance art from the late 1960s and through a period of high-to-late Modernism that would really initiate changes to the museum's environment and structure that would help shape the 'White Cube' viewer to active 'Black Cube' user 1968-2008 app.

\section{The Displaying of Analogue Video Art in Museum Structures 1968-1990 App}

From the 1960s live media installations and Performances which would include video art would become increasingly prominent in traditional and Modernist galleries altering the way audiences would experience art in the gallery/museum. In the late 1960s, the early form of analogue video art would emerge from an experimental culture and practice which frequently comingled live Performance events with art as a way to challenge tradition and the status quo of art. Yet from the outset, much of its exhibition within the hierarchical contexts of the traditional and Modernist gallery's architectonics would often mesh awkwardly. In 1966, visual and performance artist Robert Rauschenberg would intermingle art and technology in his Performance work Open Score (Bong) at the show/event Nine Evenings: Theatre and Engineering held at the Ninth Regiment Armory, N.Y. At this show:

....approximately five hundred volunteers were gathered in a totally dark playing area performing simple gestures that were recorded by infrared cameras and projected onto three large screens. ${ }^{4}$

While the show did not take place in a gallery, it would, in a sense foreshadow the track that art and Performance installation and its merging with art and technology would take within museums/galleries during a period of High Modernism as soon after this time, analogue video art would be incorporated into mainstream museum/gallery exhibitions. ${ }^{5}$

Although at first shown in a small gallery in 1963 at the Gallerie Parnass in Wuppertal, West Germany, ${ }^{6}$ when analogue video art was first exhibited in a mainstream art museum circa late 1960s (such as MoMA) there had really only been two main types of museums in existence - the Classical (or traditional) type established in 1793 by the Louvre (the first real public museum), and the avant-garde or Modernist model as defined by MoMA's 'White Cube'. In fact, preceding the establishment of the 'Black Cube' style museums of today the model of the Louvre - a Classical temple for art influenced by the Enlightenment concept of reason had always exhibited its art within inflexible gallery spaces organized in a strict historical sequence and order throughout the museum. This curatorial structure would map a route for the museum visitor who would inspect the art in the Louvre that was positioned in a strict and fixed sequence that could form a chronological hierarchy based upon art historical doctrines and classification as they traversed from gallery to gallery within the museum.

\footnotetext{
${ }^{4}$ Ibid., 38.

${ }^{5}$ Leading the way MoMA had been the first real mainstream museum to exhibit video art which it did in its Machine as Seen at the End of the Mechanical Age exhibition in 1968. This proceeded exhibitions at the Centre Pompidou, the Tate Gallery and AGNSW. Barbara London, 'Introduction to Video Spaces: Eight Installations'.

${ }^{6}$ Rush, Video Art, 213.
} 
In this rigid setting, the Louvre's objects would be linked sequentially to demonstrate that life is not a random situation providing a material starting point for the systematic and controlled study of heritability, heritage, similitude, assemblage (of parts or qualities) which it would present as a narrative or story of progress in relation to various past cultures and civilizations. Within this overall scheme, the wall space of its galleries are covered from top to bottom with paintings creating a mosaic effect covering nearly all of the museum wall — with art usually judged most important positioned at eye level, with works deemed less so arranged above and below. The other main museum type had been MoMA's 'White Cube' avant-garde art museum model which would be defined by a bare exterior and almost 'clinical' interior which suspends the artworks within a decontextualized setting by positioning single paintings at eye level (or just below it). ${ }^{7}$

Yet, within a period of High Modernism, while both museum frameworks would differ from one another in all manner of ways, both in curatorial terms would display their artworks in a strict hierarchical sequence founded upon doctrinaire art historical theories largely prescribed within inflexible architectural environments. In these contexts, prior to the development of today's 'Black Cube' or 'Black Box', viewers would pick and choose the course of their journey, which they would usually control in a self-guided way, including the amount of time they may take for viewing a particular artwork, how its meaning may unfold and how much control over it they may have, since traditional forms of art such as traditional painting and sculpture are relatively static and mute inviting passive contemplation. Yet in contrast to these static forms in the gallery, analogue video art/video installation's enunciation would depend on the audience's live participation/ interaction with the work itself. As a result, often the space surrounding the video work would be altered, as new meanings of space would need to be provided for audiences experiencing video art's strong theatrical time-based properties which would decline conventional ways of viewing traditional art provoking the audience's participation in a kind of two-way electronic kinesthetic experience or exchange that would be analogous to the condition of a kind of electronic theatre within the traditional gallery. It would do this by making the audience the subject of the object or work since early analogue video art (by contrast with more traditional art forms) would be something that audiences would not need to stand back and contemplate with awe from a distance as they would a traditional work such as the Mona Lisa -in the case of video, audiences were expected to provide meaning to the work through their active participation.

In contrast to other types of artwork, when static Minimal works by Frank Stella or Donald Judd or Cubist or Surrealist paintings by Picasso and Dali were being shown in traditional and 'White Cube' galleries based upon the Louvre's or MoMA's paradigms 'single-channel' analogue video works, as a dominant early form of video art, in situ, in their cuboid containers, would more closely resemble the domesticity of television and questions concerning how it ought to be viewed or read would be raised. In some early analogue video artworks by Fluxus musician and visual artist Nam June Paik or Frank Gillette, Peter d' Agostino, Joan Jonas or British video pioneers David Hall and Stuart Marshall for example, just to name a few, opaque and flashing colors and blurred details of sometimes a ceaseless variation would create and display an imagery that would randomly reference (or appeared to reference) other artworks and images in the wider culture of the present, as well as the past, which would make these works seem sometimes indistinct, too ephemeral and hard to comprehend

\footnotetext{
${ }^{7}$ Staniszewski, 64-5.
} 
within the permanent fixture of a traditional and Modernist gallery. ${ }^{8}$ In such a setting, would such works need to be interpreted as television as sculpture, as furniture?

While sometimes rather confusingly appearing (particularly from a distance within the gallery) to resemble - in relation to the bulk of their compositional imagery - the appearance of traditional films - some upon closer inspection, would comprise 'non-fictive' imagery lacking an easily recognizable conventional linear narrative found within traditional films. ${ }^{9}$ Positioned in the gallery as a new form of sculpture, and set in 'real time', many were long (most being over 10 minutes in duration). As a result, for audiences globally more often used to experiencing the duopoly of static two-dimensional painting or three-dimensional sculpture the durational breadth of these video works in the same context mixed with the complexity of fixing comprehension into a strict temporal framework of the video work would command more than one viewing at a time within a period of High Modernism.

In London in 1976, the Tate Gallery's Video Show would reveal the particular challenges posed by video art practitioners to the Tate's traditional fixed viewing environments. The exhibition would also present the first real test for the Tate to position, display and institute this form of modern-day kinetic art as an interpretative category. ${ }^{10}$ The show focusing directly upon the video artworks of six British artists (in pairs) over a three week period (Roger Barnard, David Hall, Brian Hoey, Tamara Krikorian, Stuart Marshall and Steven Partridge) would reflect a consciousness of the medium's developing international existence in mainstream Modernist museums such as MoMA. ${ }^{11}$ In the show, David Hall's work consisted of a single TV monitor, video camera and mirror, which had attempted to trace the passage of time in a gallery space. Both monitor and camera lens facing the viewer (the camera lens positioned directly behind and above the monitor) would be placed on a table downstairs in a lecture room in the basement of the Tate's Education Department. Hall's installation had been an attempt to catalogue the pure objectivity of the 'real time' movement of the viewer. This would be attempted by using a clear Polaroid shutter to capture at intervals the viewer's actions which would be transformed as images "...onto the camera's vidicon signal plate" which would then be released via the television monitor soon after the recorded movement. ${ }^{12}$ Through this, Hall's video art installation would attempt to investigate through the viewer "...the progressive recession of his own tracks through space". ${ }^{13}$ (Reproducible in real time through technology). In this way, the work would be reliant upon the specific use of a single monitor which would abridge the construction into a pointed dissection of process. In addition to Hall, Stuart Marshall's video work Orientation Studies (1976) would repeatedly show

\footnotetext{
${ }^{8}$ Because of the multiplicity of unquantifiable and randomized imagery which had formed its compositional and constituent parts problems had often arisen for viewers trying to extract a singular fixed interpretation from video works. Seen in this way, the video work as a 'non-text' is comprised by a total flow of imagery which is spewed forth or emitted and as such any attempt to analyze its single or fragmentary elements in motion is unattainable. Jameson, 74-78.

${ }^{9}$ Discussed as existing as the index to the zeitgeist for the high-to-late Modernist period (approximately 1968-1990) by Fredric Jameson, video art had manifested/existed as an indistinct medium. This had been due to the ever changing system of elements (exemplified by the fleeting nature of elements to be often found in the bulk of the video artwork's compositional imagery), which would be commensurable to a wider field of total flow of randomized images within any definable social period. Ibid., 67-96.

${ }^{10}$ Hall, 21.

${ }^{11}$ Ibid.

12 Cork.

13 Ibid.
} 
rapid alternating sequences revealing within the work's diegesis “....waterfalls and more gently flowing streams". ${ }^{14}$ In the Tate's Classical temple for art environment these would attempt to challenge the viewer's equilibrium, poise, cognition and perception as they were obliged to step over every monitor within the Tate's basement in order to see the other side of the podium containing the other monitors which were all linked in tandem. As Cork stated, "... all the artists demanded an active, questioning response to the monitor". ${ }^{15}$ Positioned out of the way in the Tate's basement the show would be indicative of much of the treatment analogue video art would receive by the institutions in the early days of its exhibition.

Yet, unlike traditional painting and sculpture and other contemporary installation, in order to prevent light reflecting on the video monitor screens, many of these single monitor analogue video artworks had needed to be experienced in darkened settings in the gallery. ${ }^{16}$ Despite the fact that these single channel/monitor time-based works had demanded to be communicated to an audience, in suitable and sympathetic contexts, rather than being found an optimal position, they often would be positioned awkwardly behind stairs, near toilets or in basements with electrical cables adding to the disorder due to the need for a power supply and were often passed by museum visitors. Often reduced to mere decoration in the gallery, it became an attribute of the form itself which would cause traditional art institutions to situate them apart from other art forms. ${ }^{17}$

Larger 'Environmental' video installations would pose further challenges to the fixed framework of the traditional/ Modernist museum. Alongside static installations such as Carl Andre's Bricks, Robert Morris or Richard Serra's minimal sculptures for example, large video installations would produce electronic environments reminiscent of 'entertainment arcades' which would hark back to the nineteenth century and Victorian times helping to shape a different view of the museum and the meaning of gallery space. In the U.S., Dan Graham's time-based 'total environmental' video installations - many which appear to aspire to be 'total environmental artworks "18 - would explore the extent of viewer perceptions within different kinds of viewing environments within museums. Graham, a seminal figure of video art exhibiting his video works in the U.S. from the late 1960s had posed significant challenges to fixed traditional and Modernist gallery paradigms. His environmental video installation Present Continuous Past(S) (1974), which comprises a closed-circuit time-based analogue video system, would, within a period of High Modernism, assimilate the audience's participation within the work's active diegesis. A work such as this employing a feedback loop of objectification via a video camera and monitor which continually presents a filmed image of everything occurring in a room with an 8-second delay between the point of recording and presentation would challenge the fixed frameworks of traditional museums in such a way that they would need to create specifically designed rooms (with mirrored walls) in order to present it. Other large environmental analogue video installations (each usually needing specific areas to be set aside for them) such as Campus's Interface (1972), Export's Autohypnosis (1969/1973) Nauman's Performance Corridor (1968-70) Live Taped Corridor

\footnotetext{
${ }^{14}$ Ibid.

15 Ibid.

${ }^{16}$ Day, 37.

${ }^{17}$ As a response, the overall redefinition of boundaries for viewing art in the gallery would for example, occur through MoMA's pioneering recontextualization of video art into a new museum context by its initiation of a separate area for video exhibition in 1974. 'The Museum of Modern Art Biennial Report', 43.

18 That is, works that would attempt to alter the environment they would be situated in.
} 
(1969-70) and his Going around the Corner Piece (1970 had also performed the ability to strongly oppose hierarchical museum exhibition space within a period of High Modernism. In Performance Corridor, a confined passageway comprising two wooden 'floor-to-ceiling' parallel walls positioned in the gallery would, like Present Continuous Past(S) confront audiences with their own filmed image from a surveillance camera. At one end of the tunnel two video monitors (showing the length of corridor space) would bid the audience to enter into a specifically built video environment within the gallery space, which would modify the inside of traditional and Modernist galleries into becoming an area for live performance and a 'total experience of art'. In traditional and Modernist gallery space, within a period of high-to-late Modernism Nauman's Going around the Corner Piece would closely film audiences going around a closed rectangular box in a theatrical game of 'hide and seek' whilst viewing themselves on video monitors fed by video cameras hung from above. This would particularly reveal the restrictions of a 'White Cube' space as viewer-participants, experiencing the work within the gallery's physical conditions would be invited to actively critique the internal framework of the traditional 'cube'. In order to install such works, mainstream museums would need to consider reshaping their viewing environments and interior symmetries into spaces for play, which would go against the exhibitory logic of pedagogy in more Modernist and Classical display environments.

Over time, analogue video art as a participation-based sculptural form would gradually morph from single-channel monitors narrowcast in galleries to more spectacular installation forms heavily dependent upon complex equipment. This change would particularly arise during the 1980s when corporate sponsorship assumed a much more prominent rank within the major institutions of art. From the mid-1980s the videowall system often comprising large amounts of video monitors stacked up high became increasingly prominent - the influential video artist Paik's monumental Tricolour Video (1982) would consist of 384 monitors consisting of a series of video tapes with selections from his other smaller video works such as Global Groove (1973), Suite 212 (1977), Guadalcanal Requiem (1977-79) and Lake Placid $80 .{ }^{19}$ In these contexts, the audience's interpretation would become an essential element which each institution would endeavor to control. ${ }^{20}$

\section{Towards the Black Cube: A New Modern Art Museum Paradigm}

With such time-based interventions taking place within museums/galleries, circa mid-1970s, the global sovereignty of MoMA's 'White Cube' paradigm for Modern art exhibition would defer to new developments in contemporary museum practice as a new category for art and museums would be necessitated due to the existing categories within museum structures being broken down. As a result, 'anti-hierarchical' or non-sequential spaces for categorizing the art display would be built into art institutional structures in other parts of the world to enunciate the new unconventional nature of time-based (total work) electronic technology communication, for which Modernist (or more traditional museums) had originally not been intended. Based on the notion that museums of art should be for everybody and epitomize everyday life a new museum type would be designed to present a wider range of art or total

\footnotetext{
19 'Centre national d'art et de culture Georges Pompidou Rapport d'Activite 1982', 28.

${ }^{20}$ At the Tate Modern's Uniliver Exhibition Series which I attended in June 2000 Bruce Nauman's Good Boy, Bad Boy 1985 and other major video works were positioned in the corridor where visitors often walked straight past.
} 
art and interactive experience such as video art exhibition - (which would particularly increase within the gallery from 1968-1990). Hence, the art institution's rationale and function from around the mid-1970s would encourage a transformation of the quiet contemplative almost sacred (or 'church-like') 'White Cube' spaces which had been initiated by MoMA, as museums gradually would increasingly become playgrounds for entertainment/information.

For MoMA, while it had been especially pioneering in its various practices from 1929, by the 1960s its propagation of a sacred space that separated art from the outside world was seen by many as dated. This was regrettable as it had endeavored over the years to become more accessible through a succession of refurbishments and expansions. Phillip Goodwin's and Edward Durrell Stone's attempts in 1939 to produce a more flexible gallery space by introducing movable walls within the museum, which furnished it with over 56,000 square feet of space and over 25,000 square feet of exhibition space, had resulted in its exhibition spaces practically maintaining their limited institutionalized inflexibility. ${ }^{21}$ This had even been so even though many of its rooms had been adapted to allow in more daylight with the installing of outsized windows which could take in light from the world outside. Its 1951 and 1964 refurbishments produced "...a seven-story wing for offices, classrooms and a gallery....added on the site of a townhouse west of the museum" 22 and a Phillip Johnson extension which had given it "...its first large free-span exhibition spaces" anticipated for more modern-day art would move it from an intimate to impersonal institution. ${ }^{23}$ Due to this, "...The Museum of Modern Art became a pastiche of its former self and the prototype of the deadly white cube". ${ }^{24}$ Much of its overall failure to modify its structure can be assigned to the fact that its programming "....and presentation of art...was too good an investment to part with preempted experimentation". ${ }^{25}$ This observation had typified the art institution's failure to adjust to the new issues and dimensions necessary for displaying new forms of cultural production (such as analogue video art). ${ }^{26}$ As such, in contrast to MoMA - as Montaner and Oliveras point out, during this time:

A whole new series of spaces and equipment became essential: cinema, video rooms, audio-visual rooms...museum programmes have diversified and there is a demand for a clear spatial structure to enable the public to choose which rooms they want to see or which services they want to use. ${ }^{27}$

This epic digression from traditional and Modernist's museum paradigms would result in a return to the pleasure principle of the first private Renaissance museums which would help pave the way for the development of the 'Black Cube' for the twenty-first century. ${ }^{28}$ Because of this new kind of museum, by the late 1970s there would be three types of museum in existence: Classical, Modernist, and flexible temple. The latter type, prominently celebrated by the Centre Pompidou (est. 1977) in Paris would attempt to be commensurate with the

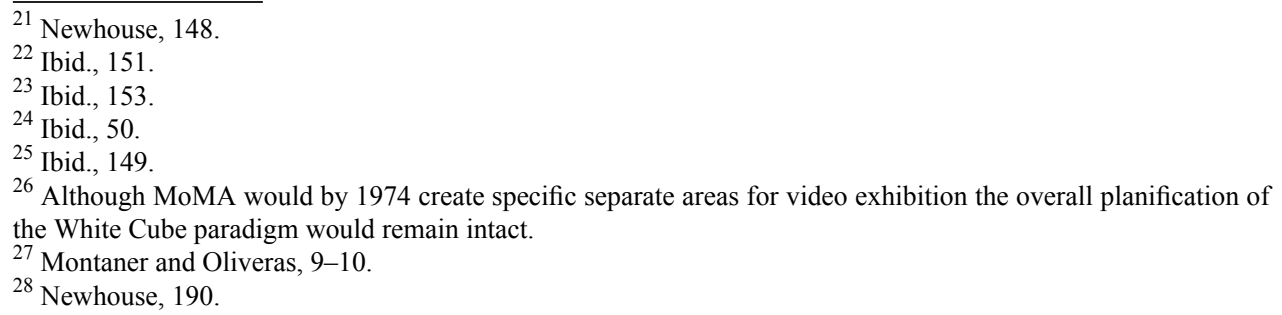


artworks contained within it (and aspire to be a 'total work' of art itself or Gesamtkunstwerk), which could showcase a new space for culture as entertainment, and in many ways, would pave the way for what many museums have become today, that is, a much more interactive, immersive and cinematic and flexible space.

By contrast with MoMA's 'White Cube' paradigm, through its random 'non' or 'anti-sequential' approach to art display, the Pompidou's particular internal spatial arrangements would provide a new spatial domain for modern art display which could 'envelope' or 'encapsulate' a set of new spatial ideas for modern museum design. The Pompidou would present a more flexible possibility for analogue video art to extend within site-specific and spectacular assemblages which would develop out of that flexibility acting as a kind of forerunner to the accessible 'Black Cube'. By comparison with MoMA's 1964 'White Cube' renovation and expansion project (which had furnished it with 63,000 square feet and over 16,000 square feet of exhibition space), the Centre Pompidou's total 1,000,000,000 square feet, comprising 183,000 square feet of exhibition space, would be employed to provide its schemes for temporary installation with a 'scenography' that would furnish analogue video art and video installation for which its "...exposed coloured ceiling ducts and beams" would furnish a flexible visual framework. ${ }^{29}$ In contrast to MoMA's 'White Cube' paradigm, the Pompidou's variable interior planning would be established to 'encapsulate' rather than 'define' or set parameters for art installation helping initiate the 'Black Cube' museum for the twenty-first century.

In order to propagate and present its vast space as 'culture' and to emphasize the Pompidou's "... decisive importance as entertainment" above all else for a mass audience, four levels would be built underground and five levels above ground. ${ }^{30}$ On the top floors (from 1977-1981) would be the MNAM which would propagate the Pompidou's permanent collection of modern art. On other floors of the Centre, immense spaces with moveable panels and walls would be situated to randomly communicate many temporary modern and contemporary art exhibitions (such as analogue video art). As a forerunner to the 'Black Cube' museum paradigm of the twenty-first century, by establishing itself as a 'pleasure-house' and 'flexible temple' its large built environment designed to disavow boundaries, categorization or any hierarchical view of knowledge (unlike the Louvre or MoMA's 'White Cube'), would incorporate new time-based installations in very many different areas of the Centre. This had been to particularly encourage a freer more egalitarian experience of modern and contemporary art - that could be more directly experienced through the public's senses. As an architectural achievement, Montaner and Jordi compare the Pompidou's design with the past structures of art museums (from the Louvre to MoMA) by stating that:

If we take as an example a nineteenth-century museum conceived solely as a series of rooms, galleries and rotundas, we can appreciate just how new this contemporary programme is and how difficult it would be to remodel and modernize a traditional museum without significant spatial transformations. ${ }^{31}$

\footnotetext{
${ }^{29}$ Ibid., 148-97.

${ }^{30}$ Ibid., 194.

${ }^{31}$ Montaner and Oliveras, 10.
} 


\section{Digital Art and the 'Black Cube' (1990-2008 app.)}

By the early-to-mid 1990s, in much of the new art produced there would be a cognitive interchange from analogue video art to digital art. Digital art/computer art would have its roots in traditional art and would be part of an electronic evolution that would follow video art. With the expansion of digital technologies during the 1990s, museums would take keen interest in presenting the new art form. The ideas for building a different type of art museum (which began within a period of High Modernism), would evolve into the creation of new art spaces designed to fit the many new works which were a combination of video, digital/ multimedia. Although a 'mechanized medium, ${ }^{32}$ digital art's possibilities would appear almost infinite. In contrast to the 'White Cube', with computer information always changing, being produced and manipulated, the computer's ability to produce its own reality, rather than reproduce reality, would produce the need for a new type of museum as increasing amounts of digital imagery would be produced. Many new digital artworks such as Jean-Pierre Yvaral's Synthesized Mona Lisa, (1989), Keith Cottingham's Untitled (Triple) (1992), Victor Burgen's Angelus Novus (1995) and Bill Seaman's Passage Set/One Pulls Pivots at the Tip of the Tongue (1995) (to name a few) would be displayed in darkened more immersive interactive spaces within a new type of museum in which audiences would be invited to interact and participate.

Today in the twenty-first century these 'Black Cube' style venues now include The New Museum of Contemporary Art New York; The Matthew Marks Gallery and The Paul Morris Gallery New York; The Max Protetch Gallery New York; Postmasters Gallery New York; Julia Friedman Gallery New York; The Hirshhorn Museum and Sculpture Garden Washington; The Palm Beach Institute of Contemporary Art PBICA Florida; Matt's Gallery London; The Lisson Gallery London; The Foundation for Art and Creative Technology FACT Liverpool; The ZKM Museum of Contemporary Art Karlsruhe; Kunsthalle Bern Switzerland; The Australian Centre for the Moving Image ACMI Melbourne and The Museum of Contemporary Art MCA Sydney. These museums, all particularly intentionally conducive to the display of video, digital and multimedia works evolved from the incorporation of time-based installation - in particular analogue video, which (Postmodern in nature) had posed problems to the fixed environments of the traditional museum within a period of High Modernism 1968-1990 app.

\section{References}

'Centre national d'art et de culture Georges Pompidou Rapport d'Activite 1982', 1982.

Cork, R. '8x8x8 Tate Gallery', Evening Standard Review http://imaging.dundee.ac.uk/partridge/www/steve_pages_sun/pages2/8X8X2.HTMs\#anchor507837, 1976 (accessed 18 April 2006).

Day, C. 'Absorbing Summer Blend: David Rosetzky.' Like (Winter 2000): 37.

Duncan, C. and A. Wallach. 'MOMA: Ordeal and Triumph on $53^{\text {rd }}$ Street.' Studio International (January-February, 1978): 48-57.

'The Universal Survey Museum.' Art History (December, 1980): 448-69.

Hall, D. 'Video.' Studio International (January/February, vol. 193, no. 985, 1977): 21.

Jameson, F. Postmodernism Or, the Cultural Logic of Late Capitalism. London: Verso, 1991.

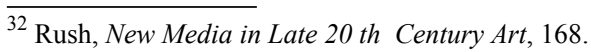


London, B., 'Introduction to Video Spaces: Eight Installations', <http://moma.org/exhibitions/1995/videospaces/london.html>, 1995 (accessed 12 March 2005).

Manasseh, C. 'The Problematic of Video Art in the Museum 1968-1990.' Ph.D. diss., The University of Western Australia, 2008.

Montaner J. and J. Oliveras. The Museums of the Last Generation. London and NewYork: St. Martin's Press and Academy Editions, 1986.

Newhouse, V. Towards a New Museum. New York: Monacelli Press, 2006.

Rush, M. New Media in Late 20 th Century Art. London: Thames and Hudson, 1999. Video Art. London: Thames and Hudson, 2003.

Staniszewski, M. A. The Power of Display, A History of Exhibition Installations at The Museum of Modern Art. Massachusetts and London: The MIT Press, 1998.

The Museum of Modern Art, 'The Museum of Modern Art Biennial Report 1976-78', New York: The Museum of Modern Art, 1978.

\section{About the Author}

Dr. Cyrus Manasseh

I am deeply committed to understanding new theoretical perspectives in art and contemporary culture particularly the role institutions play in influencing the public. I recently completed a PhD in museology at the University of Western Australia (2008) titled: "The Problematic of Video Art in the Museum (1968-1990)". I studied film and art at Reading University and also philosophy at University of London and media at the University of Greenwich in London. At the University of Western Australia, since 2004, I was coordinator, lecturer and tutor of seminars in art/architectural history and film. Publications include "Changing Museum Environments: Global Articulations of the Video Text [1968-1990]" and "The Cairo Museum, the National Museum of Athens, the Ancient Iran Museum and the Louvre: Curatorial Practices from East to West and Back". My short-term objective is to be active in arts research and education. 


\section{The International JOURNAL \\ the ARTS IN SOCIETY}

Volume 4

From Passive White Cube Viewer to Active Black Cube User: Tracking Changes in Museum Environments via "Interactive" Installation Art (Analogue to Digital 1968-2008)

Cyrus Manasseh 
THE INTERNATIONAL JOURNAL OF THE ARTS IN SOCIETY

http://www.arts-journal.com

First published in 2009 in Melbourne, Australia by Common Ground Publishing Pty Ltd www.CommonGroundPublishing.com.

(C) 2009 (individual papers), the author(s)

(C) 2009 (selection and editorial matter) Common Ground

Authors are responsible for the accuracy of citations, quotations, diagrams, tables and maps.

All rights reserved. Apart from fair use for the purposes of study, research, criticism or review as permitted under the Copyright Act (Australia), no part of this work may be reproduced without written permission from the publisher. For permissions and other inquiries, please contact <cg-support@commongroundpublishing.com>.

ISSN: 1833-1866

Publisher Site: http://www.Arts-Journal.com

THE INTERNATIONAL JOURNAL OF THE ARTS IN SOCIETY is peer-reviewed, supported by rigorous processes of criterion-referenced article ranking and qualitative commentary, ensuring that only intellectual work of the greatest substance and highest significance is published.

Typeset in Common Ground Markup Language using CGCreator multichannel typesetting system

http://www.commongroundpublishing.com/software/ 